\title{
Uma contribuição da semiótica para a comunicação visual na área da saúde
}

Sandra Regina Ramalho e Oliveira ${ }^{1}$

Débora da Rocha Gaspar ${ }^{2}$

Guilherme Augusto Ramalho e Oliveira ${ }^{3}$

RAMALHO E OLIVEIRA, S.R.; GASPAR, D.R.; RAMALHO E OLIVEIRA, G.A. A contribution from semiotics towards visual communication within the field of healthcare. Interface Comunic., Saúde, Educ., v.13, n.29, p.409-20, abr./jun. 2009.

An analysis model proposed by JeanMarie Floch is presented as a possible tool for creating and evaluating visual communication within the field of healthcare, and in particular for educational campaigns. Starting from introductory questions relating to semiotics, certain concepts common to discursive semiotics and esthetic semiotics are laid out, as postulated by Floch. A model based on the semantic opposites of euphoria and dysphoria is then presented. The paper ends by demonstrating the application of the model to a poster from a preventive campaign against smoking-related diseases.

Keywords: Persuasion. Health promotion. Visual communication. Semiotics.
Apresenta-se um modelo de análise proposto por Jean-Marie Floch como possibilidade para a criação e avaliação da comunicação visual na área da saúde, especialmente em campanhas educativas. Parte-se de questões introdutórias acerca da semiótica, expõem-se alguns conceitos comuns à semiótica discursiva e a semioestética, conforme postulado por Floch, e apresenta-se o modelo que tem a euforia e a disforia como oposição semântica de base. Ao final, mostra-se a aplicação do modelo em um cartaz de uma campanha preventiva contra doenças provocadas pelo fumo.

Palavras-chave: Fazer persuasivo. Promoção da saúde. Comunicação visual. Semiótica.
1 Graduada em Licenciatura Plena em Educação Artística: Artes Plásticas. Departamento de Artes Plásticas, Centro de Artes, Universidade do Estado de Santa Catarina. Rua Esteves Júnior, 463, apto. 601. Centro, Florianópolis, SC, Brasil. 88.015-130 ramalho@udesc.br ${ }_{2}$ Graduada em Licenciatura Plena em Educação Artística: Artes Plásticas. Universidade do Vale do Itajaí, SC. ${ }^{3}$ Médico. Secretaria da Saúde do Município de Biguaçú, SC. 


\section{Semiótica: um campo de relações}

Neste artigo queremos chamar a atenção para as possibilidades de contribuição da semiótica discursiva e da semioestética para a apropriação dos efeitos de sentido de elementos significantes de imagens em processos de comunicação na área da saúde. Trata-se de tentar estabelecer um campo de intersecção entre universos científicos por si só complexos, os quais se colocam em interação quando da construção e veiculação de campanhas preventivas, de caráter educativo, na área da saúde. Isto quer dizer que a operacionalização de modelos da semiótica possibilita tanto a diversificação das práticas de pesquisa em saúde, quanto em educação e comunicação. Acreditamos na importância da apropriação de fundamentos teóricos e modelos de análise da semiótica às equipes de caráter multidisciplinar, uma vez que campanhas preventivas são de grande responsabilidade social, pois o enunciatário, ou o destinatário da comunicação, é o coletivo, o público.

O enunciador, ou o autor do discurso, pode ser, na maioria das vezes, um publicitário ou um designer. Entretanto, quanto melhor preparados, tanto os profissionais da educação quanto os próprios profissionais da saúde, em relação aos fenômenos de significação, melhor poderão julgar o trabalho daquele outro profissional, o que vai traduzir aquelas necessidades sociais em imagens. O profissional da saúde, por sua autorizada competência, é o enunciador primeiro e o responsável pelo enunciado e por suas consequências, mesmo não sendo ele o criador das imagens. Daí esta proposta, fundamentada na semioestética, considerada uma subárea da semiótica discursiva.

Existem diversos, e muito bons, trabalhos acerca da semiótica contemporânea, mas, para alcançarmos nosso propósito, há necessidade de antepor aqui algumas palavras sobre esta área de conhecimento. Isto porque a semiótica aparece hoje como um campo de estudo específico, que cresce e se consolida, embora, por muitos, seja visto como novo.

A leitura de toda e qualquer linguagem é fundamental, mesmo, para a sobrevivência do homem sobre a Terra. Considerado um precursor da semiótica, o médico grego Galeno de Pérgamo já tinha afirmado, em inícios do primeiro milênio da era cristã, que a diagnóstica é a parte semiótica da medicina, dando origem à semiologia médica. Todavia, aqui não vamos nos ater às questões da diagnose, mas aos efeitos de significação em textos imagéticos de campanhas de prevenção - outro campo aberto à compreensão das semioses, ou seja, aos processos de significação, tanto quanto aqueles sinais que os órgãos do corpo nos oferecem à interpretação.

A primeira questão que surge, geralmente, quando se pronuncia a palavra semiótica é: o que existe em comum entre semiótica e semiologia? De acordo com Odin (1990, p.16), poder-se-ia escrever um livro para estudar em detalhes a totalidade das definições propostas para cada uma destas duas palavras; no entanto, ele destaca três possibilidades: considerá-las sinônimos, sendo apenas diferenciadas pelo fato de semiologia ser um termo mais utilizado na Europa e, semiótica, nos Estados Unidos. A segunda possibilidade, apontada por Odin, consiste em se reservar a palavra semiologia para a tradição "saussureana" (teorias dos seguidores de Saussure), e, semiótica, para a tradição "peirceana" (teorias dos seguidores de Charles Sanders Peirce). O objetivo não é apenas diferenciar seus pais fundadores, mas distinguir seus modelos teóricos e corpos de referência: estruturalismo no caso da semiologia, e pragmatismo, no da semiótica. A terceira relação entre semiologia e semiótica apontada por Odin diz que, na França, semiótica é frequentemente usada para designar as teorias propostas pelo francês Algirdas Julien Greimas; são postulações que pretendem dar conta do fenômeno da produção de sentido em geral, diferenciando-a, assim, da semiologia européia, que se ocupa do estudo da estruturação das linguagens, além da sua produção de sentidos. Outro uso diferenciado se faz ao atribuir o termo semiótica à grande área; e, semiologia, a linguagens específicas, como a semiologia do teatro ou a semiologia da informática. Daí denominarem-se os estudos semióticos na área da saúde de semiologia médica.

Esta polêmica entre os termos semiologia e semiótica atenuou-se a partir de 1969 quando, por proposição de Roman Jakobson, a Associação Internacional de Semiótica passou a adotar o termo comum - semiótica - para designar todo o campo de estudo abarcado tanto pela semiologia quanto pelo que vinha sendo denominado de semiótica; contudo, quando associada a determinados campos, como o da medicina, permanece o uso do termo semiologia, consagrado pela tradição. 
A palavra semiótica é derivada do grego semeion, que significa signo. E signo é tudo que significa, reduzindo-se a termos mínimos. Trata-se de uma palavra polissêmica, como já foi afirmado anteriormente; e as várias correntes teóricas dentro da semiótica a definem de acordo com sua visão respectiva específica. Algumas dessas conceituações podem ser complexas, mas podem se iniciar por definições sucintas, como: semiótica é a ciência geral dos signos; também pode ser considerada como a ciência da significação, ou ciência que estuda todas as linguagens; ou, ainda, "ciência que tem por objeto de investigação todas as linguagens possíveis, ou seja, que tem por objetivo o exame dos modos de constituição de todo e qualquer fenômeno de produção de significação e de sentido" (Santaella, 1989, p.15). Também pode ser definida como "ciência geral de todos os sistemas de signos através dos quais se estabelece a comunicação entre os homens" (Coelho Neto, 1983, p.17); ou conforme Odin (1990, p.12), inspirado em Greimas: "teoria geral dos sistemas de comunicação, capaz de possibilitar o estudo do conjunto dos processos de produção de sentidos, seja intervindo nas linguagens verbais, não verbais ou no mundo natural"; semiótica também pode ser considerada como um conjunto de meios que tornam possível o conhecimento de uma grandeza manifesta qualquer que se propõe conhecer, "tal qual aparece durante e depois de sua descrição" (Greimas, Courtés, 1989, p.409).

Em um estudo para quem quer ter uma visão ampla da semiótica contemporânea, Nöth (1999) apresenta os aspectos mais relevantes de diversas abordagens semióticas desenvolvidos durante o século XX. Nele, a organização dos temas faz coincidir cada capítulo com uma das distintas proposições que convivem em nossa época; e são dez os capítulos. Por seu turno, Santaella (1989) destaca mais duas das principais vertentes, além daquela que é fundamento de seus estudos, qual seja a Semiótica Peiceana, uma das linhas ou escolas mais reconhecidas no âmbito da semiótica. Isto porque seu fundador foi o norte-americano Charles Sanders Peirce, o qual deixou uma vasta produção teórica que talvez não tenha sido mesmo, até hoje, completamente explorada. O ponto de partida de Peirce não foi a língua natural, como no caso de outras vertentes. Peirce, que era filósofo e matemático, criou uma teoria dos signos associada à lógica, cuja função seria a de classificar e descrever todos os tipos de signos.

A segunda linha, citada por Santaella, é a chamada Semiótica Russa ou Semiótica da Europa Oriental, que teve como objeto de estudo, nos seus primórdios, a linguagem verbal. Esta escola, depois de vários desenvolvimentos nas teorias e após algumas mudanças geopolíticas, deu origem à Semiótica da Cultura.

A terceira das fontes destacadas por Santaella (1989) nasceu e vem se desenvolvendo com mais consistência na Europa ocidental; é conhecida como Semiótica Saussureana (por conta de Ferdinand de Saussure), Semiótica Francesa (mesmo que vários de seus seguidores sejam de outras nacionalidades), Semiótica Discursiva. Para esta vertente, cujo nome de Algirdas Julien Greimas é um marco, o foco principal são os processos de significação, e não as classificações das linguagens.

Jean-Marie Floch (1997, p.235), falando acerca das finalidades da semiótica, lembra um diálogo entre seu mestre Greimas e uma pessoa que ele chamou de "um espírito simples", fato acontecido em público. A pessoa perguntou para que serviria a semiótica. E Greimas respondeu: "serve para não falar disparates!". Essa passagem presta-se também para argumentar sobre a relevância da proposta que estamos aqui defendendo: a aquisição de referenciais semióticos para ampliar as possibilidades de autoria e apreensão da visualidade, ou seja, para uma comunicação mais efetiva em Saúde Pública.

Floch, semioticista francês, foi um dos diversos colaboradores de Greimas, tendo participado do grupo conhecido como École de Paris. Nasceu em 1947 e faleceu, aos 54 anos, precocemente, portanto, vítima de câncer de pulmão; ele era fumante. Floch delimitou e intitulou, como se fosse uma espécie de subárea da semiótica discursiva, o campo da sua produção intelectual: a semioestética. Trata-se, como se pode deduzir, da associação dos conhecimentos estéticos aos semióticos; e dessa associação nasceram instrumentos para o acesso às imagens visuais como linguagem. Isto porque, quanto aos textos verbais, os conhecimentos semióticos, por si só, já seriam suficientes, em se tratando de pessoas alfabetizadas. Mas para um enunciatário se posicionar perante um texto visual, a adição do repertório que a estética oferece é fundamental.

Embora tenha vivido pouco, sua extensa obra, publicada em livros, revistas científicas ou apresentada em congressos e seus anais, aborda a construção da significação em textos visuais os mais diversos. Entre eles podemos citar a publicidade de medicamentos, que será a referência principal deste artigo, a seguir. Além desse estudo, Floch analisou: a construção de significações em tiras, ou histórias em 
quadrinhos, anúncios publicitários, logomarcas, obras de arte, objetos do cotidiano, ou até mesmo os efeitos de sentido do trajeto de passageiros no metrô.

Floch trabalhou em colaboração com Greimas, com ele partilhando muitos dos conceitos fundamentais da semiótica discursiva; mas também deixou um legado próprio, vital para aqueles interessados em processos de significação da visualidade. Isto se deve aos seus estudos iniciais em história da arte, antes de introduzir-se na semiótica.

Importante se faz ressaltar que consideramos limitado o fato de serem abordados conceitos e fundamentos acerca da semiótica e da semioestética, ainda que introdutórios, em apenas um artigo. Todavia, acreditamos que o fato de se disseminarem estudos pioneiros e ainda não divulgados na nossa língua, bem como o de chamar a atenção para a possibilidade de desdobramentos nas mais diversas áreas, ambos o justificam.

\section{Alguns conceitos operacionais}

Não obstante, antes de apresentarmos um exemplo para reflexões sobre textos visuais de campanhas preventivas, é necessário um breve comentário acerca de alguns conceitos próprios da semiótica discursiva, para o encadeamento de idéias apresentadas neste texto. Entre eles, encontram-se: contrato de veridicção, plano de expressão e plano de conteúdo, e o par opositor disforia e euforia.

Contrato de veridicção é uma expressão usada, em semiótica, para designar a relação que se estabelece entre o enunciador e o enunciatário, ou o emissor e o receptor, a respeito do conteúdo a ser veiculado pelo texto, neste caso, pelo texto visual. Isto porque posições anteriores preocupavam-se com a transmissão da verdade, isto é, da aparência mais aproximada possível da pessoa ou coisa que a imagem pretendia representar. Vemos isto na arte acadêmica, icônica, realista, análoga ao mundo natural. Entretanto, estudos mais aprofundados mostram quanto tais imagens eram idealizadas, o que, em última instância, quer dizer, distantes da realidade retratada.

A semiótica discursiva prega a imanência de qualquer texto visual, ou seja, o texto não "representa" outra coisa, pois ele é autônomo; mesmo que pretenda estar no lugar de determinada imagem, ele será um novo texto. Assim, se ele não "representa" outra imagem, não há por que se preocupar com sua veracidade. Isto quer dizer que não há uma verdade a ser transmitida, mas um "dizer-verdadeiro", por parte do enunciador, e, na outra ponta, na ponta do enunciatário, há um "crer-verdadeiro". Conforme Greimas e Courtés (1989, p.486), "é esse equilíbrio, mais ou menos estável, esse entendimento tácito entre dois cúmplices mais ou menos conscientes que nós denominamos contrato de veridicção".

Diante de, por exemplo, uma natureza-morta, mesmo que dentro de normas estéticas que a caracterizem como hiper-realista, esse realismo não coincide com a realidade: por mais que pareça verdadeira, a tela não é tridimensional como a realidade, a luminosidade é fabricada, as dimensões, provavelmente, são diferentes da cena retratada, e as cores, do mesmo modo, não parecerão exatamente todas iguais. O enunciatário sabe disso e o artista, mais ainda, tem essa consciência. Trata-se do mesmo fenômeno batizado com a expressão "lógica de Papai Noel", por Baudrillard (1990), quando se refere à publicidade: todos, mesmo as crianças, sabem que ele não existe, mas todos nós fingimos acreditar.

Este é o contrato de veridicção - uma espécie de acerto tácito entre o enunciador e o enunciatário, a respeito da veracidade da imagem, sobre o qual Greimas ainda assim se manifesta, mais adiante:

não se imagina que o enunciador produza discursos verdadeiros, mas discursos que produzem um efeito de sentido "verdade"; desse ponto de vista, a produção da verdade corresponde ao exercício de um fazer cognitivo particular, de um fazer parecer verdadeiro que se pode chamar, sem nenhuma nuance pejorativa, de fazer persuasivo.

(Greimas, Courtés 1989, p.487)

Eis aí o conceito de persuasão de Greimas. Geralmente, entende-se que, quando há persuasão, um dos sujeitos do discurso fez prevalecer sua opinião sobre a do outro. Como os meios para tanto são 
indiferentes, inclusive os antiéticos, e como fica subjacente a noção de um ganhador e um perdedor, temos escrúpulos em relação ao ato de persuadir. Entretanto, independentemente da nossa vontade, comunicar é um ato de persuasão.

Com base em posicionamentos da semiótica discursiva, apresentamos algumas contribuições, para que observemos possibilidades - e limitações - da linguagem visual, quando se trata de processos de comunicação com o grande público, em campanhas educativas.

A semiótica discursiva trabalha com modelos de análise diversos. Entretanto, uma forte marca dessa linha teórica são as análises que partem de "oposições semânticas de base". São oposições elementares, como: belo $\times$ feio; bom $\times$ mau; bem $\times$ mal; natureza $\times$ cultura - geralmente um valor positivo contraposto por um negativo. Isto porque um ato de linguagem qualquer leva sempre em consideração as relações, pois alguma coisa só é o que é, em comparação com outra de sua classe, que é diferente. Por exemplo, o bom é bom em relação ao mau, grosso modo. Análises pautadas pela semioestética pressupõem relações, neste caso, comparações entre os elementos estéticos visuais que compõem as imagens. Assim, esses parâmetros podem ser usados tanto para a leitura visual como para a construção de uma imagem, ou seja, tanto pelo enunciador como pelo enunciatário.

Floch (1997, 1995), entre os diversos modelos de análise que propôs e aplicou, apresenta um modelo que foi usado especificamente na análise da publicidade de medicamentos. Ora, se alguém está doente, de antemão já tem um valor negativo em si, o mal que lhe aflige, o qual o obriga a consumir o medicamento. E o remédio tem como princípio devolver-lhe a plena saúde (valor positivo). Assim, o que se espera é que a publicidade, assim como a embalagem do medicamento, apresentem um discurso coerente com a promessa de saúde (um valor positivo).

Daí a escolha, por Floch, dos conceitos de euforia (valor positivo, efeitos de sentido da saúde) e disforia (valor negativo, efeitos de sentido de doença) para oposição semântica de base, no estudo sobre as imagens da publicidade de medicamentos. À euforia podem se atribuir os efeitos de sentido relacionados à alegria, prazer, tranquilidade e calma; à disforia, os sentidos de tristeza, ansiedade, dor e angústia. Mas como se traduzem estes significados (plano do conteúdo) positivos e negativos em formas e cores (plano de expressão)?

Então, aqui é necessário fazer a inserção de outros dois conceitos da semiótica discursiva: plano de expressão e plano de conteúdo. A significação, em cada imagem, é resultante da conjugação de dois planos que se estruturam de maneira interdependente. Trata-se de postulação introduzida por Saussure e retomada, posteriormente, por seus seguidores, com destaque especial às formulações e desenvolvimentos realizados por Hjelmslev (1991), então aplicados apenas à linguagem verbal: o plano da expressão, onde elementos constitutivos ou diferenciais selecionam e articulam as qualidades de que um código se utiliza para se manifestar; o plano do conteúdo, onde a significação nasce das articulações entre estes elementos diferenciais.

Posteriormente a Saussure e Hjelmslev, esses conceitos - e modos de funcionamento - foram retomados por Greimas. Então os semioticistas da visualidade que trabalharam com Greimas, na edificação da semiótica de linha francesa, como Floch e Thülermann, extrapolaram esses planos para o significante visual.

É importante ressaltar que, embora cada um desses planos se organize como subsistemas da imagem ou do texto, entre eles inexiste qualquer tipo de hierarquia, assim também como não há autonomia de um em relação ao outro. Ao contrário, entre plano de expressão e plano de conteúdo, ou seja, entre significante e significado, ou entre sintaxe e semântica, o que há, permanentemente, é a interdependência e a reciprocidade.

Assim sendo, uma imagem adquire visibilidade, legibilidade e produz significação, independentemente do fato de poderem vir a ser estabelecidas ou não relações de ordem análoga ou icônica entre o plano de expressão e o plano do conteúdo. Isto é importante destacar: imagens ou elementos de imagens que não se assemelhem a nada reconhecível existente no mundo natural, ao contrário do que pensa o senso comum, também significam.

Talvez não tenham um significado hermético e preciso, mas efeitos de sentido, muitas vezes intraduzíveis em palavras. Daí a opção preferencial pelo uso da expressão efeitos de sentido em lugar da 
palavra significação. Sendo assim, aqui queremos então "mostrar as coerções gerais que a natureza de tal plano de expressão impõe à manifestação da significação" (Hjelmslev, 1991, p.53), ou seja, que o plano de expressão, visível e legível, é que determina os efeitos de sentido (plano do conteúdo).

\section{As categorias estéticas euforia e disforia}

Floch, no seu estudo sobre a significação de propagandas de medicamentos, identificou doze possibilidades estéticas no plano da expressão, as quais correspondem, no plano de conteúdo, aos efeitos de sentido de euforia; e, igualmente, trabalhando sempre com pares oponentes, propôs o mesmo número de possibilidades estéticas que correspondem às significações de disforia. Importante se faz aqui destacar que os conceitos de euforia e disforia, em semiótica, não têm os mesmos significados do que em psiquiatria; como pode ser observado, não se trata de estados do sujeito. São atributos sensíveis das imagens que, dada a percepção e recepção, podem gerar efeitos de sentidos para os sujeitos.

São os seguintes os elementos estéticos que contribuem para a construção do sentido de euforia, conforme proposto por Floch (valor positivo, efeitos de sentido de alegria, prazer, tranquilidade e calma): claro, gradativo, colorido, sutil, contínuo, nítido, alto, simples, simétrico, único, conjunto e pictórico. Por oposição, são elementos estéticos que levam à noção de disforia (valor negativo, sentidos de tristeza, ansiedade, dor e angústia): escuro, contrastante, monocromo, denso, descontínuo, desfocado, baixo, complexo, assimétrico, múltiplo, disjunto e gráfico.

E justapondo os pares, temos: claro $\mathrm{x}$ escuro; gradativo $\mathrm{x}$ contrastante; colorido $\mathrm{x}$ monocromo; sutil $\mathrm{x}$ denso; contínuo $\mathrm{x}$ descontínuo; nítido $\mathrm{x}$ desfocado; alto $\mathrm{x}$ baixo; simples $\mathrm{x}$ complexo; simétrico $\mathrm{x}$ assimétrico; único $\mathrm{x}$ múltiplo; conjunto $\mathrm{x}$ disjunto; pictórico $\mathrm{x}$ gráfico.

Segundo assinala o autor, em cada publicidade de medicamento analisada, mesclam-se esses procedimentos; entre as diversas imagens analisadas, os efeitos de sentido não eram exclusivamente disforia ou euforia. A construção da significação nas imagens assemelha-se a uma rede de elementos trançados, não lineares. Mas o que prepondera é que vai determinar a força desses efeitos sensíveis um vetor de efeitos de sentido, cujo discurso deve ser coerente com a finalidade do seu objeto (a publicidade de um medicamento, uma campanha educativa). E usando palavras do próprio Floch, "a saúde é euforia ou ao menos, não-disforia".

Importante também se faz ressaltar a preferência pela expressão "efeitos de sentido" ao invés, simplesmente, de "significados". "Efeitos de sentido" é uma expressão ampla que, ao mesmo tempo, respeita a complexidade da tessitura de qualquer imagem, "experiência aberta", ou "tudo o que de incompleto existe na imagem ou no espetáculo [...]" como disse Eco (1972, p.96), que é a autoria do enunciador uma das pontas do ato de linguagem; e a expressão "efeitos de sentido" contempla igualmente a diversidade cultural, social e, mesmo, intelectual do sujeito enunciatário - a outra ponta do ato de linguagem, o público composto não por uma massa uniforme de seres, mas por indivíduos, e como tal, distintos em seus modos de apreender significações.

Como resultado do estudo específico de Floch, foi observado que, na maioria das propagandas dos medicamentos analisados, predominavam os efeitos de sentido de disforia (valor negativo). Ele intitulou o trabalho de recusa da euforia e, no subtítulo, acusa a indústria farmacêutica de estar em desacordo com os médicos (Floch, 1997), pelo simples fato de que o objetivo do medicamento - e dos médicos é a cura, um conceito eufórico. Todavia, esta é apenas uma síntese desse trabalho de Floch, por demais extenso para uma análise mais acurada neste espaço, já que aqui o objetivo é chamar a atenção para o potencial da semiótica em campanhas educativas, mais do que a análise de um estudo específico, o qual é apresentado apenas como exemplificação.

Este mesmo modelo foi usado em outro estudo, na Universidade do Estado de Santa Catarina (UDESC), em um Trabalho de Conclusão de Curso de Design, de autoria de Mariana Pereira da Silva. A designer pretendia fazer um estudo sobre design de superfície, que é o design plano, como os tecidos e todo tipo de cobertura de janelas, paredes e móveis. A escolha do objeto de estudo, ou seja, neste caso, o ambiente a ser analisado, tinha como critério ser um lugar público, um local que conversasse com a população. A escolha recaiu sobre a ala infantil do Hospital Universitário da Universidade Federal de Santa Catarina (UFSC), em Florianópolis, por natureza um espaço de conflito entre euforias e 
disforias de distintas origens. Embora existissem outros modelos de análise disponíveis, por ter sido adequado para o estudo de medicamentos, a opção foi pelo modelo euforia $x$ disforia: ele tinha também em comum, como destinatários, pessoas doentes (ou seus pais).

Em síntese, uma primeira avaliação mostrou que não havia planejamento para além da obra civil; não havia uma padronização no visual dos espaços, e cada ambiente parecia ter sido feito com critérios diferentes, em momentos distintos. Mesmo as cores das paredes pareciam estar condicionadas apenas ao gosto da pessoa responsável no momento no qual se precisou pintar. Estes dados foram posteriormente confirmados por entrevista. Os próprios funcionários, no intuito de adequar o espaço às crianças, pintaram murais com trenzinhos, flores e outros estereótipos do que seja o anseio de comunicação visual que agrade à criança. Ou seja: o design de superfície ainda não tinha chegado à ala infantil do Hospital Universitário, o que levou a autora do estudo ao conceito de pré-design, e a intitular seu trabalho de: "Pré-Design: efeitos de significação de um ambiente hospitalar infantil concebido por leigos".

Por falta de mais material, o que não desqualificava o trabalho, ao contrário, a opção foi analisar três painéis de parede. Do mesmo modo que os resultados da pesquisa de Floch, as conclusões apontam para a predominância de elementos disfóricos na comunicação (chamemos a atenção para isto: aqueles painéis não consistem em mera decoração, pois estão, permanentemente, a emitir sentidos!) das paredes da ala infantil do Hospital Universitário. Embora coloridos, predominavam elementos gráficos, complexos, assimétricos. Como exemplo, o trenzinho citado estava em um plano descendente e não ascendente.

Uma imagem que não foi analisada, mas causou impacto sobre a pesquisadora, foi um poster com anjinhos entre nuvens no céu, na sala de espera dos consultórios da ala infantil, mais uma escolha ingênua e leiga naquele ambiente. Só para lembrar, chamamos as crianças de anjo ou anjinho apenas como metáfora. Mas, na tradição religiosa, apenas se torna anjinho quem morre. Talvez não fosse adequado lembrar aos pais e seus "anjinhos" que eles poderiam, em breve, se tornar, de fato, anjinhos; e que aquela sala de espera poderia ser a antessala do céu.

Neste caso, o problema não estava apenas na composição plástica, na estética do cartaz (plano de expressão); o problema estava na temática (plano de conteúdo). Todavia, esta imagem, com seu caráter simbólico cheio de obviedades, não consistia em uma imagem mais complexa, profissional, destinada a um grande público. De acordo com os resultados do estudo, após a análise do campo visual ao qual estavam submetidos - pois é um local que não se escolhe -, doentes e seus parentes indicaram a necessidade de um tratamento profissionalizado ao ambiente hospitalar, como anunciava seu próprio título. E esta intervenção profissional pressupunha uma equipe multidisciplinar, envolvendo profissionais da educação e da saúde, além do designer.

\section{Campanhas educativas na área da saúde: euforia ou disforia?}

Parece-nos relevante a contribuição da semiótica na comunicação visual de campanhas educativas na área da saúde, como em qualquer área que envolva a massa populacional, pois há uma questão ética subjacente, que está inclusa no fazer persuasivo. É importante que se saiba que o plano de expressão pode sublinhar os efeitos de sentidos; ou pode confundir a recepção das idéias, embora um leigo não perceba. Do mesmo modo, é importante conhecer as noções de euforia e disforia - e de como elas se constroem, para que a comunicação atinja os objetivos propostos.

Em alguns casos, como nas campanhas de prevenção da aids, pode ser necessário que as imagens passem, ao público, efeitos de sentido disfóricos, além da disforia da temática (plano de conteúdo), que, por si só, já o é e vem sendo abordada enquanto tal. O caso mais conhecido é o de uma peça publicitária do italiano Oliviero Toscani (2002) para a marca Benetton. Nas ilustrações desse livro, percebe-se a provocação das temáticas (plano de conteúdo) e, ao mesmo tempo, sua estetização (plano de expressão), como no caso das etnias, da guerra, da preservação ambiental. Mas no caso da aids, a propaganda de Toscani é mais significativa, pois se trata de uma cena real, a de um doente agonizando, cercado pela família.

Por outro lado, há que se levar em conta o contrato de veridicção; mesmo quando não se trata de uma imagem verdadeira, o enunciatário exercerá sua capacidade de "crer-verdadeiro", o que exige do 
enunciatário - seja ele o criador de imagens ou quem assina a peça -, a responsabilidade perante a sociedade em seu todo e a cada cidadão em si.

Assim, há mais uma decisão a se tomar, em relação a: aprovação do visual das campanhas, critérios mais complexos, aqueles relacionados apenas à temática (plano de conteúdo) ou aos elementos óbvios, reconhecíveis, do plano de expressão; e se ela deve ser estetizada ou não; são critérios além dos de originalidade, contemporaneidade ou, mesmo, os parâmetros clássicos de beleza, pautados em equilíbrio, harmonia e proporções. Trata-se das decisões relacionadas ao modo como a imagem é construída e aos efeitos que causará.

A prevenção da doença deverá gerar, na massa populacional, efeitos de sentido de saúde (euforia) ou da sua ausência (disforia)? Uma campanha para doação de sangue, por exemplo: que aspecto deve ter a imagem para melhor persuadir a população? Em uma campanha de prevenção às cáries, o que deve ser mostrado? Até que ponto os conteúdos devem ser explícitos em figuras? Ou devem estar camuflados em elementos constitutivos da linguagem visual (luminosidade, desequilíbrio, dispersão, só para citar alguns)?

E há outra questão muito cara à semiótica da discursividade, especialmente nos estudos recentes de Landowski (2004), segundo o qual o objeto de estudo da semiótica discursiva não se encerra em examinar o que dizem os textos (verbais, não-verbais ou outros), mas como dizem o que dizem.

Para concluir estas proposições, a título de exemplo, vamos tomar uma imagem de um cartaz de uma campanha preventiva contra o tabagismo (Figura 1), tendo como referência alguns conceitos semióticos e as 12 categorias de eufórico e as 12 de disfórico, no nível da expressão, buscando algumas implicações no plano de conteúdo.

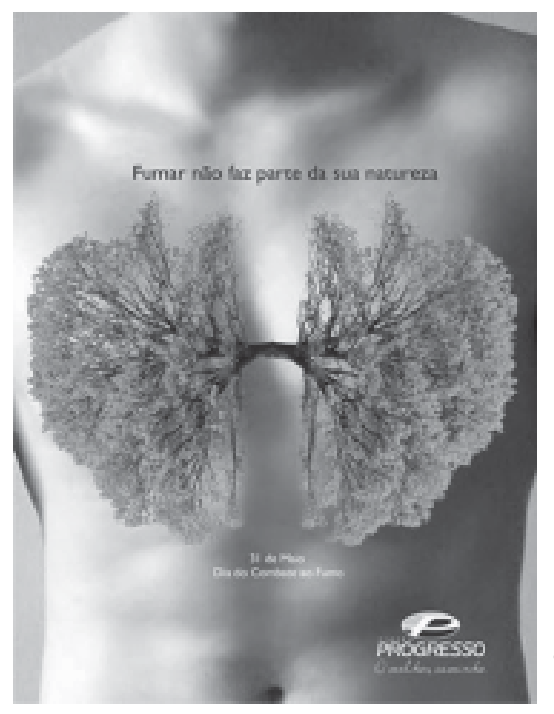

Figura 1.Campanha do Dia do Combate ao Fumo, promovida pela empresa Viação Progresso de Três Rios, Rio de Janeiro.

A imagem da campanha do Dia do Combate ao Fumo, já de início, propõe um contrato de veridicção: um simulacro de corpo humano. Não tem rosto, nem pelos, marcas, sequer o sexo pode ser definido com certeza. Devido a questões que a teoria psicológica da gestalt pode explicar melhor do que a semiótica, parece ser um corpo humano. Segundo a semioestética, temos um plano irregular, em cores (ou não-cores) que variam do cinza escuro ao branco, este causado por uma determinada luminosidade, extremamente artificial, a qual mostra essas irregularidades, que aludem à musculatura de um corpo humano, com destaque para um ponto inferior que passa o efeito de sentido de umbigo. 
O fundo também é cinza e pouco se destaca, mas não deixa de delimitar as formas humanas, pois os cinzentos do corpo e do fundo diferem entre si pelas tonalidades, ora mais claras, ora mais escuras.

Se há um contrato de veridicção para o que estamos chamando de corpo humano, contrato ainda mais necessário é o que pede a imagem em relação às formas sobre o corpo - e não dentro dele, ambiguidade óbvia entre os pulmões e a simulação de árvores, colocadas lateralmente sobre o corpo, em posição espelhada, ambas do mesmo verde.

O conteúdo verbal do texto visual, "fumar não faz parte da sua natureza" relaciona pulmão/natureza (natureza humana do enunciatário: isotopia temática); árvore/natureza (conceito comum de natureza: isotopia temática); pulmão/árvore (ambos natureza: isotopia temática; similaridade visual entre pulmão e árvore: isotopia figurativa). Como pode ser observado, há uma tessitura bem encadeada, onde os conceitos verbais e visuais se complementam ou reiteram desde que se considere o contrato de veridicção, de que aquelas formas verdes são árvores e pulmões ao mesmo tempo; e que aquelas formas sob as verdes árvores pulmonares presentificam uma pessoa, portadora de pulmões, portanto, e, consequentemente, parte da natureza.

Observemos ainda o processo de persuasão estabelecido por essas relações visuais e verbais, construídas a partir de figuras do mundo natural (árvore, pulmão, corpo humano) e dos respectivos conceitos, diretamente ligados ao plano de expressão (corpo humano, árvores, natureza, pulmões), que, neste caso, coincidentemente, consistem em figuras análogas às do mundo natural, portanto passíveis de leitura pelo senso comum.

Mas o que há a mais para se ver nesse texto, que na verdade não é só visual, mas híbrido, porque também apresenta elementos verbais? Apoiamo-nos nas categorias de Floch para diversas possíveis operações, como, por exemplo: a desaceleração do ato de ver; a desconstrução das figuras análogas às do mundo natural em elementos mínimos (pontos, linhas, planos, texturas); a penetração em efeitos de sentido hipodérmicos em relação à camada mais visível da imagem; a apreensão de morfemas visuais e verbais miméticos diante de um primeiro ou apressado olhar.

No primeiro plano, centralizado na vertical, a imagem é composta por duas massas verdes simétricas, sobrepostas ao corpo, unidas por uma pequena linha horizontal. As massas são compostas por incontáveis linhas sinuosas, que têm a forma ora de galhos de árvores, ora lembram vasos, artérias, canais intercomunicantes, enfim. Essas formas são mais claras nas extremidades; há pigmentos amarelos e azuis, formando o tom claro do verde. As texturas dessas duas grandes formas simétricas verdes e suas pequenas linhas marrons remetem a duas árvores unidas por um mesmo tronco central; as figuras são espelhadas, ou seja, rebatidas e idênticas, posicionadas diferenciadamente de como as vemos no ambiente natural, pois elas estão de lado.

Esse conjunto, estando em primeiro plano e sendo o único elemento colorido - agregando pigmentos de outras cores, além do verde, inclusive - somada a sua posição, central e horizontal, faz com que as árvores pulmonares imperem sobre a cena, dominando, consequentemente, os efeitos de sentido. Fora do verde, tudo é cinzento. Cinza, a cor das cinzas do cigarro; e é a cor que lembra o escuro dos pulmões de quem fuma. Fora da natureza (árvores), tudo é cinza.

Neste sentido, a campanha ultrapassa a dimensão de prevenção contra o fumo e, por analogia, alude a outras questões ambientais, como o desmatamento: o corpo liso totalmente, que lhe serve de fundo, que se confunde com o fundo cinza propriamente dito, é contraponto às árvores, contrastando com efeitos de sentido de terra inóspita, estéril, assexuada, ou queimada (cinza).

O fundo é simples, portanto, composto apenas por gradações de cinza, o que ressalta a luminosidade e o verde, pois há uma preponderância maior de branco do que de negro na escala tonal. Percebem-se linhas sinuosas que contornam o tronco "humano", atribuindo-Ihe movimento. Quanto às formas "pulmonares", elas são compostas por cores, linhas e texturas, que remetem a efeitos de sentido os mais diversos: além de árvore e pulmões, podem aludir a dois cérebros; a embriões gêmeos; a seres estranhos em conjunção; a bonsais enxertados; à associação de entidades coirmãs; a qualquer sistema, natural ou organizacional, que se inter-relacione ou intercomunique (pois não nos esqueçamos: na "massa" populacional existem indivíduos com os mais diversos tipos de formação e, portanto, percepção). E mesmo a imagem pode ainda aludir à duplicidade de posições e à necessidade de tomada de posição, como fumar/não fumar. 
Essas formas "pulmonares" se destacam, enfim, por sua nitidez, leveza e sutileza; os espaçamentos entre os galhos, que deixam o olhar buscar a claridade do fundo cinza claro, dando a sensação de ar livre e límpido, também ressaltada pela tonalidade do verde. E emitem novos efeitos de sentido, abertos a diversas possibilidades.

Acima dos pulmões-árvores, centralizado e em fonte preta, encontra-se o slogan da campanha, "fumar não faz parte de sua natureza", frase que intensifica, de certo modo, a sensação de leveza do ar que passa pelos pulmões-árvores que colorem a imagem. E nega, verbalmente, a presença do fumo ou de qualquer elemento visual que o presentifique na imagem, pois não há nem fumaça, nem fogo, nem cigarro, nem cinzeiro. O fumo está presente apenas no modo verbal (na palavra fumar), e como negação. No campo visual, a negação é dada pela sua ausência.

Então, em termos de elementos estéticos, na imagem da propaganda encontramos as oposições semânticas de base encontradas em palavras (conceitos) como: primeiro plano/segundo plano; figura/ fundo; verde/outra cor qualquer; simétrica/assimétrica; horizontal/vertical; central/lateral; simplicidade/ complexidade; unidade/dispersão; gradação/contraste; sutileza/obviedade; nitidez/nebulosidade; colorido/neutralidade cromática; claro/escuro.

Como podem ser observadas, essas categorias são todas categorias estéticas, no sentido etimológico da palavra estética, qual seja, de elementos perceptíveis por meio dos sentidos. Nem todas estão presentes na imagem, mas se fazem presente por potencialmente comporem um par opositor (não maniqueísta, uma vez que claro pode formar um par opositor com ambíguo ou com escuro; dispersão pode formar um par com unidade ou com concentração, por exemplo).

Assim, o acesso, o conhecimento e a familiaridade em relação a esses conceitos possibilitam ver, perceber mais elementos do que ao senso comum é permitido ver. As homologações de cada linha, de cada unidade mínima de expressão no plano de conteúdo vão se dar por meio dos inúmeros entrecruzamentos desses elementos estéticos, gerando os efeitos de sentido. Nesta perspectiva, euforia e disforia são grandes paradigmas sob os quais se organizam doze categorias estéticas de pares opositores de conceitos; ou 24 conceitos estéticos cujo mérito maior é ser o fio condutor do olhar do leigo para uma análise mais acurada, porque apropriada dos termos técnicos adequados e de seus significados correspondentes.

Concluindo a análise, na parte inferior da forma central verde, localiza-se, em fonte branca, pequena e centralizada, a inscrição "Dia 31 de maio"; e, na linha de baixo, "Dia do Combate ao Fumo". Na saída do olhar, na parte inferior direita da imagem, está a assinatura da empresa de transporte responsável pela campanha, Viação Progresso, seguida de seu slogan "o melhor caminho". Aí se dá a associação da empresa que assina a propaganda com os efeitos de sentido da imagem - ela apropriando-se do valor dos conceitos veiculados na imagem híbrida da publicidade que ela patrocina: quem não tem, na sua memória, como noção de "melhor caminho", uma antiga estrada ladeada por frondosas árvores? E o "melhor caminho" para a respiração também não é um pulmão livre do fumo? E qual o "melhor caminho" para o futuro de nossos tempos poluídos e conturbados?

\section{Considerações finais}

Os modelos semióticos para leitura de imagem, entre os quais se inclui o modelo "euforia x disforia" de Floch, não têm o objetivo de julgamento de valor, de analisar se uma campanha ou peça publicitária é "boa" ou "ruim". O que busca a semiótica discursiva é mostrar o que diz a imagem ou outros textos e, sobretudo, mostrar como eles dizem o que dizem. Também não são campo da semiótica as análises sociológicas, históricas, psicológicas. Com toda a propriedade, essas e outras ciências utilizam seus aparatos teóricos e metodológicos para analisar imagens. Todavia, a semiótica é o campo de estudo mesmo da significação das linguagens. Mas não é por esta prerrogativa que deva caber ao semioticista, por si só, definir se uma campanha preventiva deva mostrar, por meio de elementos disfóricos, os resultados da ausência de prevenção; nem, pelo contrário, se o uso de elementos eufóricos é o mais adequado, para mostrar, ao enunciatário, o público, em um certo momento, e para determinada população, como a vida será melhor sem fumo, ou sem aids, sem câncer ou sem cáries. 
Também deve ser esclarecido que o uso dos paradigmas eufórico e disfórico se deu por Floch em relação à análise de medicamentos destinados à depressão, nas quais imagens publicitárias predominantemente disfóricas eram contrárias aos propósitos médicos. Assim, em cada situação, a intencionalidade do discurso frente ao público deve ser definida, antes da criação e da análise das imagens.

Cabe ao semioticista, portanto, mostrar que, além das figuras análogas ao mundo natural, como corpos, animais, plantas, coisas legíveis por qualquer leigo, existem: linhas, formas, cores, contrastes, harmonias, sutilezas, nebulosidades, entre outros elementos e procedimentos semioestéticos, próprios da linguagem visual, uma espécie de morfemas e sintaxes que podem persuadir o enunciatário potencial, sem que ele perceba; ou um processo de persuasão sem contrato de veridicção. Ou seja, existem modos de comunicar menos explícitos, que demandam um saber específico, além daquelas construções visuais icônicas, figurativas, as que também persuadem por meio de contratos de veridicção. E mesmo as figuras "decodificáveis", aparentemente, por qualquer um podem emitir efeitos de sentidos os mais diversos, inclusive contrários aos aparentes, dependendo da sua construção formal.

Nossa posição é a de que deve caber a uma equipe multidisciplinar, sob a coordenação de um profissional da saúde, a tomada de posição sobre a abordagem a ser feita diante da massa populacional, em relação a questões de prevenção nessa área. Recomendamos, embora pareça óbvio, nunca esquecer que essa "massa" é composta por indivíduos, seres únicos, embora o conteúdo da mensagem deva atingir a todos.

Por outro lado - e talvez aqui resida a tentativa de contribuição maior deste artigo - queremos ainda destacar que este é um campo de investigação a ser mais explorado por grupos de pesquisa igualmente multidisciplinares, pois, como pode ser observado, este é um território de interfaces. A coautoria de profissionais de áreas distintas neste trabalho é um testemunho desta crença.

Investigações de campo apresentando peças publicitárias e colhendo, diretamente, em entrevistas ou questionários, gravações de vídeos ou fotos, coletando dados acerca da força persuasiva de campanhas educativas, do seu "dizer-verdadeiro", do seu "crer-verdadeiro" e, mesmo, da sua simples apreensão e compreensão, precisam ser feitas junto às diversas camadas da população.

Muitos recursos públicos e, mesmo, privados, no Brasil, são despendidos permanentemente com campanhas preventivas na área da saúde, e não sabemos como a efetividade de seus resultados é avaliada. Mesmo em um país avançado em pesquisas, como os Estados Unidos, uma publicação recente afirma que "a literatura sobre pesquisas revelou um pequeno número de estudos disponíveis que remetam à educação existente para pacientes cirúrgicos que fumam" (Lauerman, 2008, p.599).

Em nosso país, acaba de ser lançada mais uma coleção de fotografias para ilustrar carteiras de cigarro, mas não foram devidamente divulgados os critérios adotados para selecioná-las. Jornalisticamente, foi insinuado que são mais chocantes do que as anteriores. O que seria chocante? Disfórico? Quais suas características visuais concretas? Quais as relações de seus elementos, qual o enquadramento, para onde se dirige o olhar da personagem, caso haja? As pesquisas ainda poderão avançar muito sobre a significação das campanhas preventivas, não só em relação às doenças decorrentes do fumo, mas também em campanhas educativas quanto à doação de sangue, saúde bucal, controle da Aids, sempre levando em conta as interfaces entre educação, saúde e comunicação, não esquecendo dos aportes que a semiótica pode oferecer.

\section{Colaboradores}

Sandra Regina Ramalho e Oliveira colaborou na coordenação do trabalho, elaboração e redação do manuscrito. Débora da Rocha Gaspar foi responsável pela formatação, segundo as normas da revista, elaboração do resumo em espanhol, seleção e análise da imagem. Guilherme Augusto Ramalho e Oliveira colaborou no ajuste e definição do foco do texto e nos aspectos específicos da área da saúde. 


\section{Referências}

AUTOVIAÇÃO PROGRESSO. Campanha publicada no setor "Novidades". Disponível em: <http://www.viacaoprogresso.com.br/site.php?secao=novidades \&conteudo= novidades_2\&pagina $=5>$. Acesso em: 29 fev. 2008.

BAUDRILLARD, J. Significação da publicidade. In: LIMA, L.C. (Org.). Teoria da cultura de massa. Rio de Janeiro: Paz e Terra, 1990. p.273-80.

COELHO NETTO, T. Semiótica, informação e comunicação. São Paulo: Perspectiva, 1980.

ECO, U. A definição da arte. Lisboa: Edições 70, 1972.

FLOCH, J.-M. Semiotica, marketing e comunicazione. Milano: FrancoAngeli, 1997.

Identités visuelles. Paris: Presses Universitaires de France, 1995.

GREIMAS, A.J.; COURTÉS, J. Dicionário de semiótica. São Paulo: Cultix, 1989.

HJELMSLEV, L. Ensaios linguísticos. São Paulo: Perspectiva, 1991.

LANDOWSKI, E. Modos de presença do visível. In: OLIVEIRA, A.C. (Org.). Semiótica plástica. São Paulo: Hacker, 2004. p.97-112.

LAUERMAN, C.J. Surgical pacient education related to smoking. AORN J., v.87, p.599-609, 2008. Disponível em: <http://www.aornjournal.org/article/S00012092(07)00697-7/abstract>. Acesso em: 29 jul. 2008.

NÖTH, W. A semiótica no século XX. São Paulo: Annablume, 1999.

Panorama da semiótica - de Platão a Peirce. São Paulo: Annablume, 1998.

ODIN, R. Cinéma et production de sens. Paris: Armand Colin, 1990.

SANTAELLA, L. O que é semiótica. São Paulo: Brasiliense, 1989.

SILVA, M.P. Pré-design: efeitos de significação de um ambiente hospitalar infantil concebido por leigos. 2004. Monografia (Graduação) - Centro de Artes, Universidade do Estado de Santa Catarina, Florianópolis. 2004.

TOSACANI, O. A publicidade é um cadáver que nos sorri. Rio de Janeiro: Ediouro, 2002.

VESTERGAARD, T.; SCHRODER, K. A linguagem da propaganda. São Paulo: Martins Fontes, 2000.

RAMALHO E OLIVEIRA, S.R.; GASPAR, D.R.; RAMALHO E OLIVEIRA, G.A. Uma contribución de la semiótica para la comunicación visual en el área de la salud. Interface - Comunic., Saúde, Educ., v.13, n.29, p.409-20, abr./jun. 2009.

Se presenta un modelo de análisis propuesto por Jean-Marie Floch como posibilidad para la creación y valuación de la comunicación visual en el área de la salud, especialmente en campañas educativas. Se parte de cuestiones introductorias acerca de la semiótica, se exponen algunos conceptos comunes a la semiótica discursiva y a la semiótica estética, tal como postula Floch y se presenta el modelo que tiene la euforia y la ansiedad como oposición semántica de base. Al final se muestra la aplicación del modelo en el cartel de una campaña preventiva contra enfermedades provocadas por el tabaco.

Palabras clave: Hacer persuasivo. Promoción de la salud. Comunicación visual. Semiótica. 